\title{
Renewable Energy Scenarios: Exploring Technology, Acceptance and Climate - Options at the Community- Scale
}

\author{
A. M. Gormally ${ }^{\mathrm{a}^{*}}$, J. D. Whyatt ${ }^{\mathrm{a}}$, R. J. Timmis ${ }^{\mathrm{b}}$ \& C. G. Pooley ${ }^{\mathrm{a}}$
}

${ }^{a}$ Lancaster Environment Centre, Lancaster University, Lancaster, LA1 4YQ

${ }^{\mathrm{b}}$ Environment Agency, c/o Lancaster Environment Centre, University, Lancaster, LA1 4YQ

* Corresponding author: a.gormally@lancaster.ac.uk

\section{Abstract:}

Community-based renewable energy could play a key role in the transition to a low carbon society. This paper argues that given the right environmental and societal conditions, communities in the UK could source a high percentage of their electricity supply from a mixture of localised renewable electricity technologies. Here we use exploratory scenarios to assess demand and renewable electricity supply-side options at the community-scale for a location in Cumbria, UK. Three scenarios are presented, using narratives of how local demand and renewable electricity supply could be constructed under either existing or modified environmental and societal conditions. The three scenarios explored were 'Current State of Play', 'Low Carbon Adjusted Society' and 'Reluctant Scenario'.

Keywords: Energy scenarios, energy \& environment, community-based renewable electricity, climate.

\section{Introduction}

Approaches that will increase the supply of renewable energy and reduce demand are needed in response to the UK's goal of reducing carbon emissions by 2050 (Climate Change 
24 Act, 2008) and in response to the European Union's (EU) renewable energy target of 20\%

25 by 2020 (DECC, 2009). The UK has a lower target of $15 \%$ renewable energy by 2020 ,

26 however is making slow progress having achieved 7\% in 2014 (DUKES, 2015, Renewable

27 Energy Strategy, 2009). Furthermore, the UK aims to generate $30-40 \%$ of its electricity from renewable sources but to date has only achieved 18\% (DUKES, 2015). Significant changes will need to be made in the UK's approach to energy if these targets are to be met.

Although a centralised large-scale approach to energy currently dominates, there is emerging interest in distributed small-scale renewable energy, particularly where communities are involved in the ownership or management of local developments. Interest has been fuelled by the perceived benefits that locally-led developments can play in 34 increasing local acceptance of renewable technologies and in altering energy behaviours by providing real-time information to inform energy use decisions (Heiskanen et al., 2010, CSE, 2007, Warren and McFadyen, 2010). The concept of generating and using locally-owned energy is gaining popularity with residents in the UK, with the number of energy schemes labelled as 'community-based' rising to over 1000 in 2012 (Hargreaves et al., 2012). This is partly due to concerns over increasing fuel prices, with consumers wanting to become more independent from large energy providers and having more control over where their energy comes from (Butler et al., 2012, Watson et al., 2008, Gormally et al., 2013). The UK coalition government declared support for community-based activities, releasing it's first 'Community Energy Strategy' recognising the 'advantages that community-based action offers energy and climate change policy' (DECC, 2014, p.3)

45 Given the perceived relevance community energy could have in promoting low carbon 46 technologies and reducing local demand, this paper examines the technical, societal and 47 environmental aspects of local schemes by exploring the potential contributions of renewable supply and demand-side options for a case study community, using a set of 
49 exploratory scenarios. This paper argues that given the right societal and environmental 50 conditions, communities in the UK could become significant producers of electricity. As 51 shown on The Isle of Eigg (Yadoo et al., 2011), it is possible for a small community to 52 generate almost all electricity needs through community-based renewables when this is 53 the only option available. Supply-side options used on Eigg involve combining a mix of 54 renewable resources which have different seasonal and weather dependencies. By 55 combining a mix of hydro-power, wind-power and solar photovoltaics (PV), together with 5624 hour battery storage and back-up diesel generators, they have managed to overcome 57 some of the issues associated with the variability of renewable generation. This is coupled 58 with demand-side measures including a household cap of 5KW (all households are provided 59 with OWL energy meters) and by asking residents to voluntarily reduce demand in times of 60 low renewable electricity generation. Here we consider whether this concept of balancing 61 supply and demand locally through utilising local renewable resources translates to on-grid 62 rural communities on the UK mainland.

63 This paper presents the final phase of an interdisciplinary, mixed methods research project 64 that has examined community-based renewable energy in Cumbria, UK. The first phase 65 combined quantitative methods (spatial analysis and calculated energy outputs) with 66 secondary data in order to assess annual renewable resource potential at the regional scale 67 and identify areas with sufficient local resources to support a portfolio of renewable energy 68 technologies (Gormally et al., 2012). The second phase involved using quantitative and 69 qualitative methods to assess residents' attitudes to renewable energy, in three Cumbrian 70 communities. Themes included attitudes towards localised ownership of renewable energy, 71 involvement in local energy schemes and preference towards different renewable 72 technologies (Gormally et al., 2013). The communities were chosen using the results of the 73 spatial analysis conducted in the initial phase, which identified them as having high 
74 resource potential for a portfolio of renewable technologies. Subsequently, one of the

75 three communities was chosen as the focus for developing community-level energy

76 scenarios in this final phase of the overall study.

77 In this paper we use one type of energy scenario to explore possible 'renewable futures' for

78 our chosen case study community. Scenarios are a means of exploring alternative futures

79 and Kowalski et al., (2009) describe three main types that are often used - forecasting

80 scenarios (those which are a continuation of the past), normative scenarios (those which

81 aim for milestones and assume a certain future can be created) and exploratory scenarios

82 (those which explore a possible space for the future but do not aim to predict it). Here we

83 use exploratory scenarios to examine electricity demand and supply at the community

84 scale. Therefore, we do not aim to predict the future for this community, we simple aim to

85 explore plausible and potential futures based on different assumptions of technologies, 86 acceptance and climate.

87 The scenario options described in this paper are modified by both local demand and renewable supply-side conditions. Reviewing renewable supply-side options involves exploring the existing potential (current meteorological conditions) and future potential

90 (possible future meteorological conditions) by exploring the effects of climate and extreme

91 weather events. The impact of extreme weather events is important in terms of ensuring

92 security of supply, especially as extreme events in the UK are predicted to become more

93 severe and more frequent in the coming decades (Meehl, 2007, Fowler and Ekström, 2009).

94 Indeed, this has raised interest among the energy-related research community with studies

95 addressing the energy outputs and economic impact of such changes on hydro-power and

96 wind-power (Harrison and Whittington, 2002, Greene et al., 2010). The UK has seen a shift

97 in some meteorological conditions, for example, rainfall patterns are found to be changing

98 with winter rainfall events becoming more intense and more frequent in upland areas such 
99 as Cumbria (Ferranti et al., 2009, Malby et al., 2007, Burt and Ferranti, 2012, Osborn et al., 100 2000). This could have implications for renewable technologies in the future (for instance, 101 energy outputs from hydro-power). It is important to note that the aim of this paper is not 102 to model future climate for this community. That is beyond the scope of this research and 103 outside of the remit of the 'exploratory' scenario approach taken here. To help explore 104 possible impacts of climate or changing weather patterns on renewable supply-side 105 options, we take a simplified approach by using 'extremes' identified in the local 30-year 106 meteorological record (for more details see section 2.1.2).

107 Supply-side options are additionally modified by societal acceptance which is used to 108 define both the renewable technology options used and the scale of the chosen 109 technology. Demand-side options use current estimates of local residential electricity 110 demand and future estimates which explore both reduced (high awareness) and increased 111 (low awareness) levels of residential demand. For an example of all pathway options used 112 to construct the scenarios described in this paper, see Figure 1.

\section{Methodology \& Results}

114 The following methodology was used to develop exploratory energy scenarios for one

115 community in Cumbria, UK. We firstly describe the case study community followed by the

116 methods and data used to determine local levels of electricity demand and renewable

117 energy supply. Three exploratory scenarios are then constructed. These are 'Current State 118 of Play', 'Low Carbon Adjusted Society' and 'Reluctant Society'. All three scenarios 119 represent different narratives of how local demand and renewable energy supply could be 120 constructed under either existing or modified environmental and societal conditions. Each 121 scenario considers the demand and supply balance on temporal scales ranging from annual 122 to monthly and daily. To contextualise the results, each scenario considers whether the 
123 community could generate sufficient renewable electricity to satisfy three different levels

124 of local demand. Firstly, greater than $30 \%$ of the community's electricity needs; secondly

$12590-100 \%$ of the community's electricity needs and thirdly, in excess ( $>100 \%)$ of the

126 community's electricity needs. The $30 \%$ contribution was chosen in line with the UK's

127 overall target of $>30 \%$ renewable electricity by the year 2020 (Renewable Energy Strategy,

128 2009), the $90-100 \%$ contribution was chosen due to its suggested feasibility given the

129 evidence from The Isle of Eigg (Yadoo et al., 2011), and the $>100 \%$ contribution was chosen

130 to establish whether given the right conditions of environmental, societal and technology

131 mix, the community could become a net exporter of electricity to the grid. 


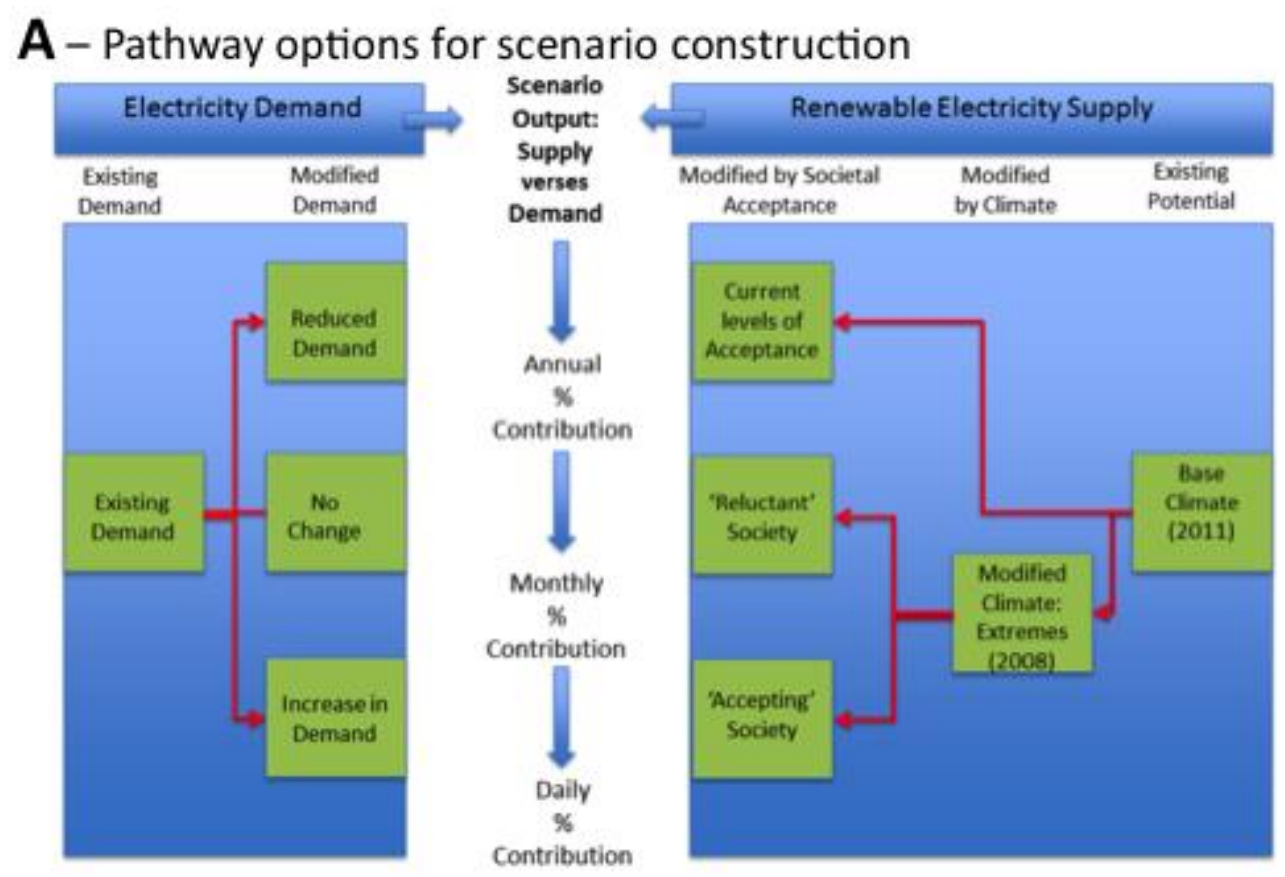

\section{B -Example scenario construction for 'Low Carbon' pathway}
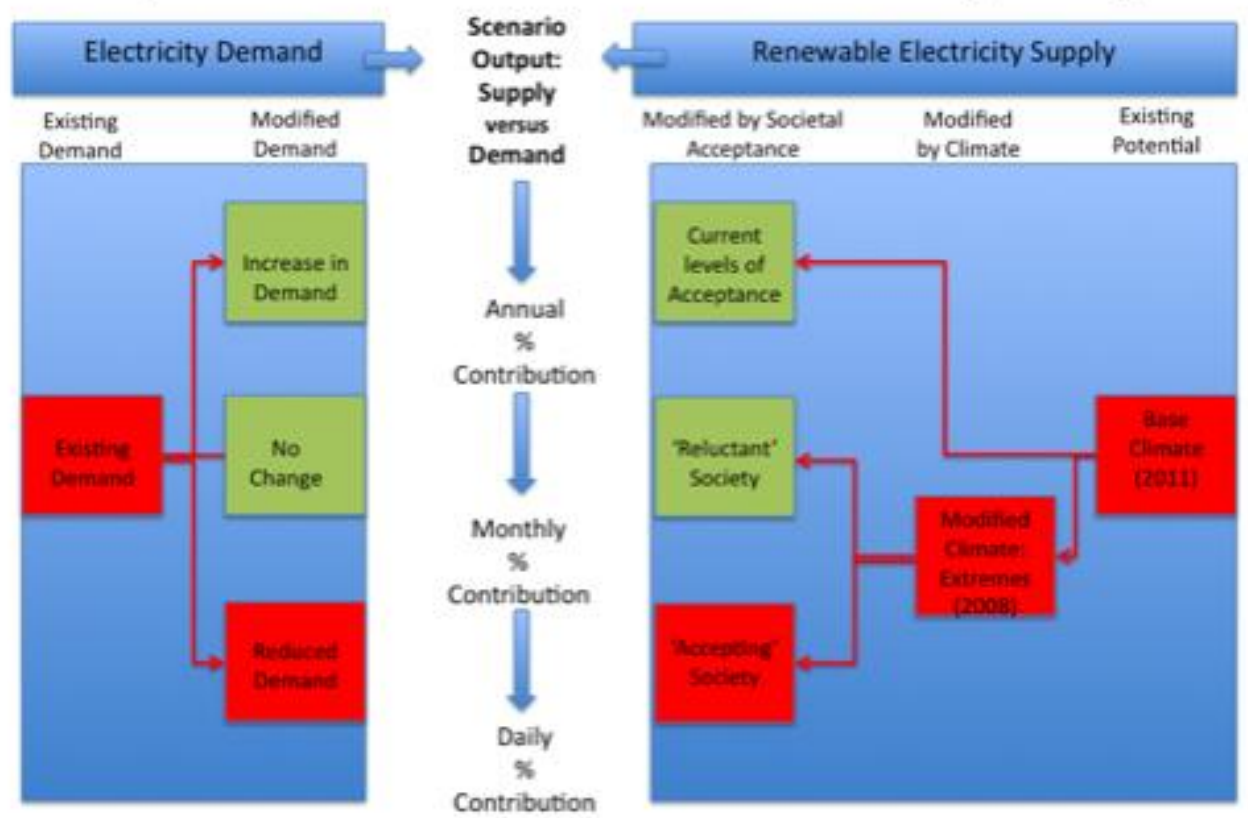

133 Figure 1. (A) Shows the different pathway options for scenario construction through

134 considering modifications of demand (ie. existing demand and increase or decrease in

135 demand), which then aligns with the chosen scenario options for renewable supply

136 electricity supply (ie. Impact of climate and societal acceptance). The scenario output

137 considers the contribution of the renewable electricity mix to annual, monthly and daily 
138 demand patterns. Figure 1 (B) provides an example pathway for the scenario 'Low Carbon

139 Society' option, with reduced demand, 'accepting' society and modified climate (increased 140 rainfall).

143 The village of Sedgwick (Figure 2) was chosen as the case study community to develop the 144 energy scenarios and explore possible 'renewable futures' at the community level. It is 145 located in the South Lakeland District of Cumbria in the North-west of England and is 146 situated between the boundaries of the Lake District National Park and the Yorkshire Dales 147 National Park. It has a population of 378 inhabitants (source: 2001 census; key statistics) 148 and achieved a high response rate $(61 \%)$ to the household questionnaire survey on 149 community energy carried out in an earlier phase of this research (Gormally et al., 2013). 150 Results of this survey indicated a high level of support for locally-led initiatives. The 151 regional scale mapping of resource potential carried out in Gormally et al., (2012) also 152 suggests that this community and its immediate surroundings could potentially support a 153 number of renewable electricity developments. For example, hydro-power, wind-power, 154 solar PV and land for bioenergy crops, specifically Miscanthus or Short Rotation Coppice 155 (SRC). 


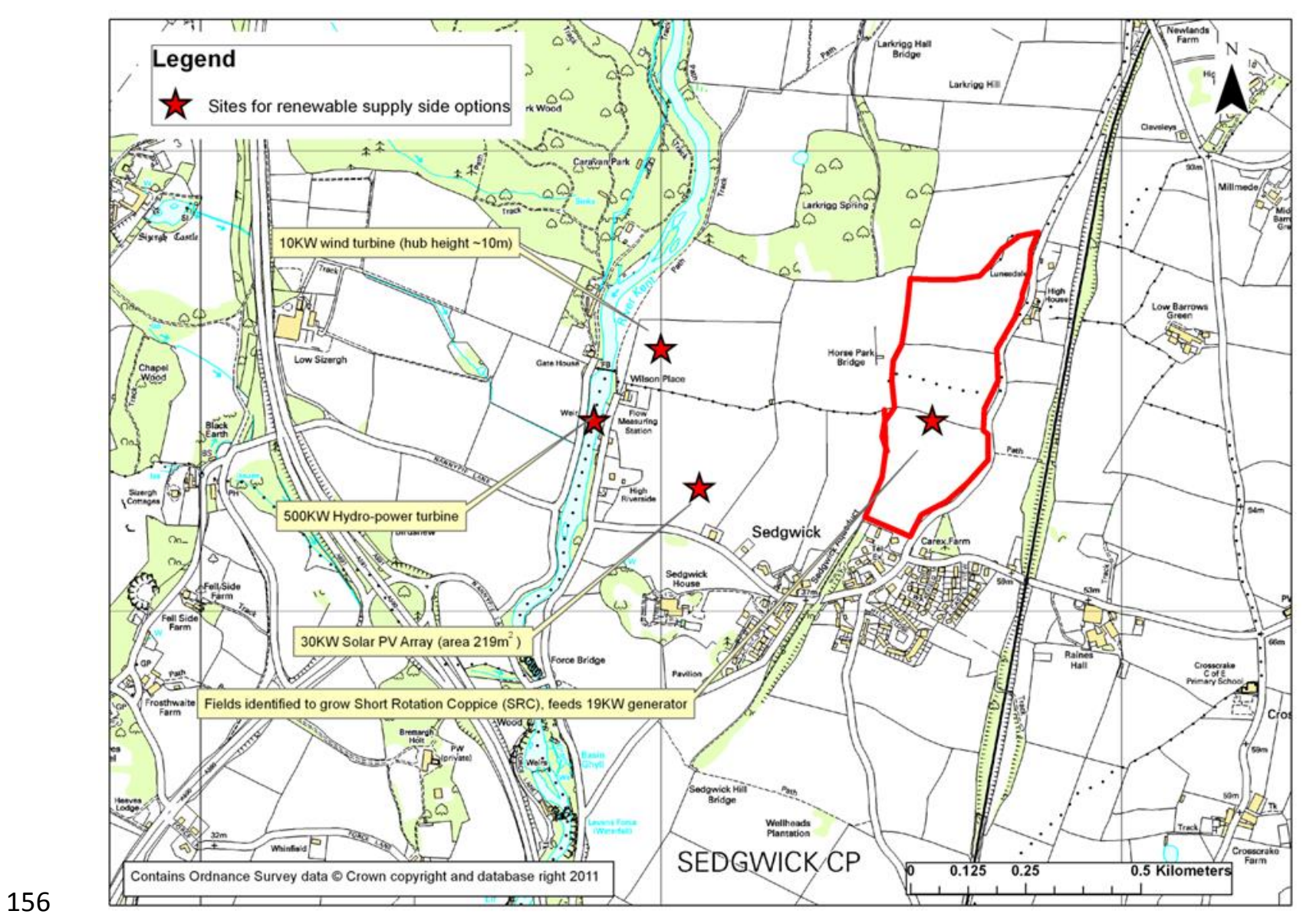

157 Figure 2. The village of Sedgwick in Cumbria showing proposed locations of renewable

158 supply-side technologies including, wind-power, solar PV array, hydro-power and land

159 identified for bioenergy (SRC) crops.

\subsubsection{Electricity Demand}

161 Existing levels of local electricity demand were derived on an annual basis. This was achieved using domestic electricity consumption data taken from the Digest of UK Energy

163 Statistics produced by the Department for Energy and Climate Change (DUKES, 2010)

164 available at Lower Level Super Output Area (LLSOA). LLSOA consist of approximately four

165 Output Areas which are used to define the UK Census. LLSOA's take into account 166 population size (mean population 1500), mutual proximity and social homogeneity (ONS, 167 2011). This electricity data has been used due to its availability over LLSOA scales, however 
168 it is acknowledged that it doesn't provide information on other factors that could 169 contribute to electricity consumption such as building type, income, occupation and 170 weather dependencies (for examples of studies considering these aspects see Azevedo et 171 al., 2015 and Azevedo et al., 2016).

172 These data revealed that the community had an annual domestic electricity consumption 173 of $4725 \mathrm{KWh}$ per household. To determine the mean annual electricity consumption for the 174 community, this value was multiplied by the number of households in the village (204 175 households) taken from the 2001 UK census of population (most recent available at the 176 time of the research). Although this approach leads to an estimate of community electricity 177 consumption rather than demand, it gives an indication of how much renewable capacity 178 would be need to be developed to match generation with demand on an annual basis.

179 Existing levels of community electricity consumption were also derived on a monthly and 180 daily (including hourly) basis. Seasonal adjustments (eg. For months DJF, MAM, JJA, SON) 181 were then applied based on seasonal patterns of UK household electricity use 182 (Sustainability First, 2012). Daily profiles were based on UK household electricity 183 consumption data taken from the Energy Saving Trust (2012) which were compared to the 184 localised outputs from above and adjustments (including daily and seasonal) were made 185 accordingly. These figures were then multiplied by the number of households in the case 186 study community.

187 Having derived current levels of household demand (consumption) two future 188 modifications were considered; one in which local demand was reduced through high 189 levels of energy awareness, and one in which local demand was increased through lack of 190 energy awareness. These demand-side modifications are based on scenarios used by DECC 191 (2012). Modifications resulting in reduced levels of local demand were based on 'policy on' 
pathways resulting in high levels of residential abatement. This results in a reduction of residential electricity consumption of $\sim 42 \%$, which was then applied to existing levels of

194 local electricity demand, described above. Modifications resulting in increased levels of

195 local demand were based on the 'policy off' pathway (also called business as usual) used by

196 DECC (2012), which implies no significant policies have been implemented to reduce

197 carbon and energy usage. This results in an increase of $\sim 16 \%$ of residential electricity

198 consumption. This modification was then applied to existing levels of local electricity

199 demand, described above.

\subsubsection{Renewable Energy Supply}

201 The village of Sedgwick has already been identified as having significant resource potential

202 to develop run-of-river hydro-power, wind-power, bioenergy (SRC or Miscanthus) and solar 203 PV (Gormally et al., 2012). Therefore these four technologies were considered as 204 renewable energy supply-side options. To determine energy outputs from supply-side 205 options, base environmental data were used from the year 2011, for example, river flow, 206 wind speed and solar radiation data. Renewable energy supply-side options were also 207 modified by meteorological extremes (referred to in this article as climate). In this study we 208 focus on extremes of river flow (data taken from the flow gauge on the River Kent at 209 Sedgwick), a decision justified by evidence showing notable changes in rainfall in Cumbria 210 and an increased frequency of extreme events (Ferranti et al., 2009, Burt and Ferranti, 211 2012). The inter-annual variability of wind speed was also examined using data taken from 212 a weather station at Hazelrigg, Lancaster, located $28 \mathrm{~km}$ south of Sedgwick. These data 213 were obtained from the British Atmospheric Data Centre (MIDAS, 2013), and adopted for 214 reasons including length of record $(>30 \text { record })^{1}$ reliability of readings and similar

\footnotetext{
${ }^{1}$ A climate period in meteorological terms is based on a 30 year time period (see UK Met Office for more details http://www.metoffice.gov.uk/climate)
} 
215 landscape to the village of Sedgwick. For further particulars relating to environmental data, 216 see Table 1.

217 On examining both the river flow and wind-speed records it became apparent that wind 218 speed varied little on an annual basis (annual mean wind-speed $5.05 \mathrm{~m} \mathrm{~s}^{-1}$ from 1977-2009,

219 SD: $0.39 \mathrm{~m} \mathrm{~s}^{-1}$ ), however, river flow showed much greater inter-annual variability (annual 220 mean flow $9.24 \mathrm{~m}^{3} \mathrm{~s}^{-1}$ from 1969-2010, SD: $\left.1.65 \mathrm{~m}^{3} \mathrm{~s}^{-1}\right)$. Therefore, for scenario options that 221 considered a modified climate, environmental data for the year 2008 were used, as this 222 was the year in which the flow deviated most significantly from the long-term (30 year) 223 annual and monthly means. Wind-speed data for 2008 was also used for a modified 224 climate, to keep meteorological and hydrological parameters consistent and to avoid 225 unnecessary 'mixing and matching' of data. In contrast, modelled solar radiation data was 226 adopted (as used for base climate) since there was no difference when modelling radiation 227 between years. No change was made to bioenergy yields as it was felt this was beyond the 228 scope of this paper.

229 Point locations for run-of-river hydro-power were pre-determined from the Environment 230 Agency's (2010) mapping study and therefore restricted to certain locations. The site 231 selected for use in this study was located by the monitoring station on the River Kent at 232 Sedgwick. This site had a potential generating capacity of between 100-500KW 233 (Environment Agency, 2010). Due to the predicted increases in rainfall (and subsequently, 234 river flow), the upper capacity of 500KW was used for the generator size. In order to find 235 locations for wind turbines the DTI's $1 \mathrm{~km}$ wind-speed data base was used to assess 236 variations in annual wind speed across the study area. 15 min wind-speed data from 237 Hazelrigg, either for the base climate (2011) or modified climate (2008), were then used for 238 the chosen location for the wind turbine to calculate energy outputs. All scenarios used 239 small-scale (10KW) wind turbines and therefore no vertical interpolation of wind-speed 
240 was necessary. Wind-speed data were recorded at $10 \mathrm{~m}$ above ground level (agl) and the 241 suggested hub-height of a 10KW wind turbine is approximately $10 \mathrm{~m}$.

242 Solar irradiance was modelled using a GIS from a 50m digital terrain model (DTM)).

243 Potential sites for the PV array were located by identifying areas of high solar irradiance

244 within fields currently not used for agriculture (eg. non-arable land). Fields were selected

245 by eye due to the small size of the study area, using Ordnance Survey (OS) Mastermap data

246 (1:2500 scale) and the Centre for Ecology and Hydrology (CEH) Land Cover Map (2007). The

247 Land Cover Map (LCM) is derived from satellite images and describes land cover for the UK,

248 for instance urban areas, water bodies, natural and managed vegetated surfaces (CEH, 249 2011).

250 For bioenergy, we assume that the community will source its own feedstock, and therefore, 251 only consider land close to or within the community boundary. The bioenergy methodology 252 first identified non-arable land (ie. areas of grassland but not semi-improved grassland 253 which are important for ecological reasons) using LCM (2007). The slope of the terrain was 254 then calculated from OS 1:10,000 scale Landform Profile data and areas with gradients < $25512 \%$ were considered as being most practical for growing crops such as SRC due to 256 harvesting constraints ie. suitable for harvesting machinery to work (Tenerelli and Carver, 257 2012). Areas of land that satisfied the land use and slope criteria and which fell in close 258 proximity to a road (essential for coppicing machinery access) were selected (Defra, 2004). 259 The total area of land available was then calculated and the number of available hectares 260 determined. A yield potential of 12 odt (oven dried tonnes) $\mathrm{ha}^{-1} \mathrm{yr}^{-1}$ was used to calculate 261 potential annual electricity output as per the methodology in Gormally et al., (2012). Yield outputs were taken from Defra's (2007) study on Opportunities and Optimum Sitings for 263 Energy Crops. A total of three fields covering approximately 13 hectares were selected, 


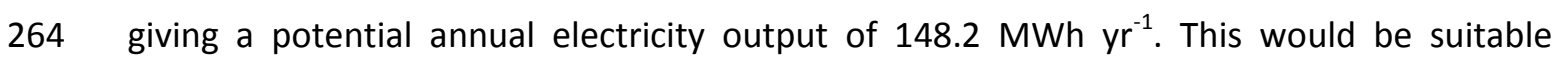
265 feedstock for a 19KW generator.

266 Renewable energy supply-side options were also modified by societal acceptance. This

267 constrained both the technology choice and scale of technologies. Information gathered on

268 what the community would be willing to accept was taken from questionnaires and

269 interviews with residents (for more detailed information on outputs from this research see

270 Gormally et al., (2013)). The modification by societal acceptance will be detailed for each

271 scenario in section 3: 'Scenario Selections and Results'.

\begin{tabular}{|c|c|c|c|c|c|c|}
\hline Resource & Renewable Technology & Dataset & Source & Data Type & Time Period & Time Resolution \\
\hline River flow & Hydro-power & Gauging Data $\left(\mathrm{m}^{3} \mathrm{~s}^{-1}\right)$ & Environment Agency & Observed & 1969-2012 & $15 \mathrm{~min}$ \\
\hline Windspeed & Wind-power & $10 \mathrm{~m}$ windspeed data $\left(\mathrm{m} \mathrm{s}^{-1}\right)$ & BADC & Observed & $1977-2012$ & $10 \mathrm{~min}$ \\
\hline Solar radiation & Solar PV & Solar irradiance $\left(\mathrm{wh} \mathrm{m}^{-2}\right.$ ) & Derived from terrain model & Modelled & 2011 & $60 \mathrm{~min}$ \\
\hline \multirow{2}{*}{ Land/crops } & \multirow{2}{*}{ Bioenergy } & Defra energy crop yield study & Defra & Modelled & - & - \\
\hline & & Land Cover Map 2007 & CEH & Observed & - & - \\
\hline
\end{tabular}

274

275 Table 1. Source and resolution of environmental data.

\section{Scenario Selections and Results}

277 Three exploratory scenarios were produced which narrate different possibilities of how the

278 case study community could balance local demand with different renewable energy supply-

279 side options. These considered pathways modified by societal and environmental

280 conditions. For all scenarios, demand and renewable supply contributions are shown

281 annually and monthly (not all the results can be shown here, however, highest and lowest 

contributions were broken down into daily profiles. This was achieved specifically for a given winter week and summer week, to highlight seasonal weather dependencies. A single day from each week was chosen to show daily and hourly profiles, an example of which is shown for the 'Low Carbon Adjusted Society' scenario. Although this only provides an example, and there will inevitably be variability both between daily profiles and between different weeks, it demonstrates how demand could be compared to renewable supply options at finer temporal scales. The following will describe the scenario options and results. Figures 3 to 5 show annual, winter day and summer day profiles.

\subsection{Current State of Play}

292 This scenario assumed existing levels of local electricity demand and existing levels of 293 renewable resource potential (base climate, 2011). Resource potential is then modified by 294 societal acceptance, using results of local preferences to renewable technologies and 295 scales. Details of the societal acceptance results can be found in Gormally et al., (2013). In 296 this scenario we assume the portfolio of hydro-power (500KW), solar PV array (30KW) and 297 small-scale wind (10KW). These options were chosen to provide a balance between 298 providing some level of seasonally inter-changeable renewable generation (ie. as achieved 299 on The Isle of Eigg) and residents' preference for specific renewable technologies. For 300 instance, wind farms and bioenergy schemes appeared to hold least favour with residents 301 in terms of perceived visual impacts, efficiency (wind farms) and land use issues 302 (bioenergy). Consequently, only small-scale wind was included in this scenario and 303 bioenergy was excluded.

304 Overall this mix contributed $11 \%$ annually to the community's electricity needs (Figure $3 \mathrm{~A}$ ). 305 The highest monthly generation is achieved in December (at 14.9\%). Although demand for 
electricity is high in winter and the contribution from the PV array is negligible, demand is

307 offset by the high levels of electricity generation from the hydro-power turbine and wind

308 turbine. The lowest monthly generation is in March (at 7.5\%) due to low performance from

309 all renewable sources.

310 This scenario was also explored for a typical winters day and summers day. On the winters

311 day, the generation from the chosen renewable mix generates double the community's

312 needs. Generation is dominated by hydro-power as a result of high winter river flows.

313 However, the same mix only contributes to $27 \%$ of the community's electricity needs on a

314 typical summers day. Although the solar PV array is now making a significant contribution,

315 low river flow and limited wind-power leave the community with a 73\% electricity deficit.

316 Demand and supply-side pathways including an overview of annual, monthly and

317 winter/summer day examples, are illustrated in Table 2.

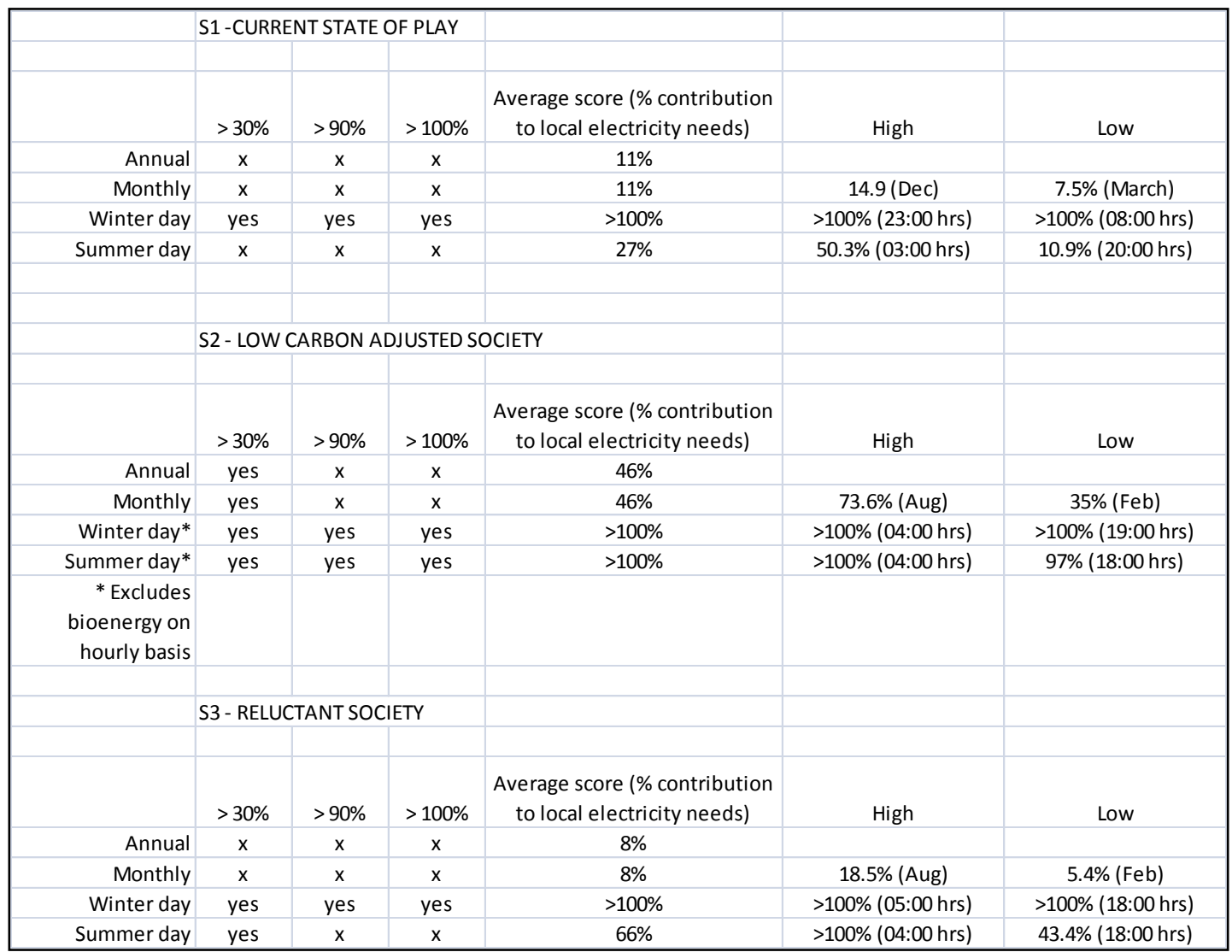


319 Table 2. Contribution to local electricity needs from the different renewable portfolio 320 options for scenarios 1,2 and 3.

322 This scenario considers the community's electricity supply and demand under favourable

323 modifications. It assumes lower levels of demand and considers renewable energy supply

324 under a modified climate (meteorological data from 'extreme' year 2008). The supply side

325 is also modified by societal acceptance in that most renewable energy technologies are

326 assumed to have become both economically and culturally acceptable. Therefore,

327 bioenergy is additionally included in the renewable supply-side mix. Short rotation coppice

328 (SRC) rather than Miscanthus is used because SRC had a higher yield potential across the 

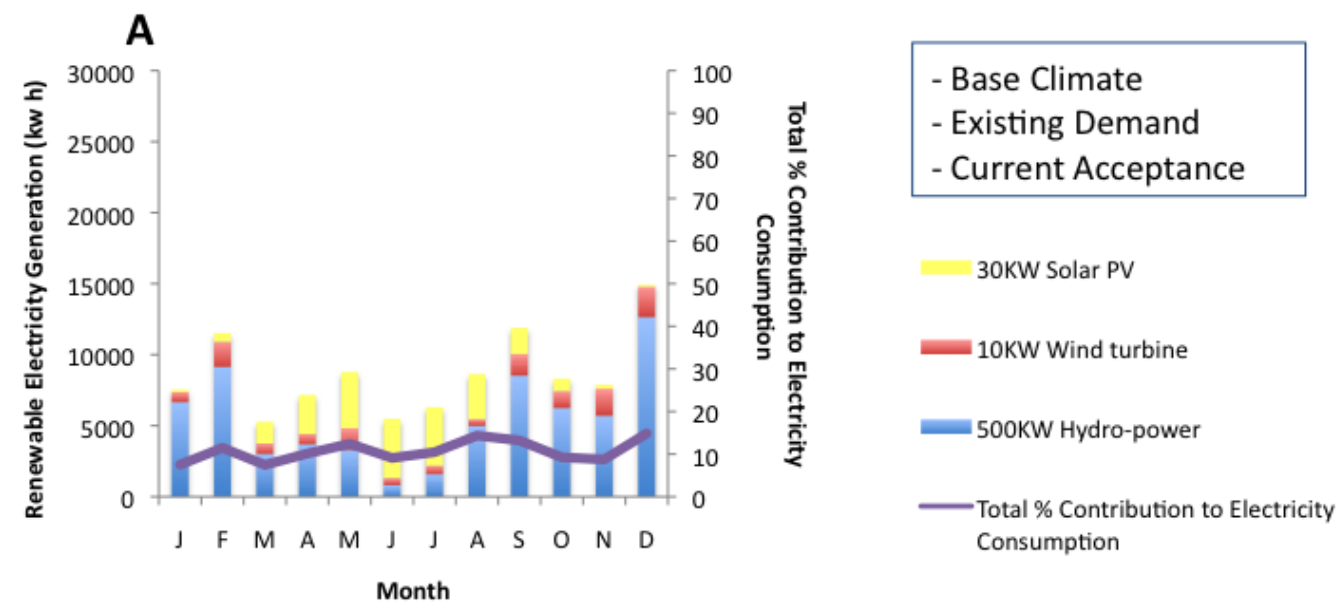

B
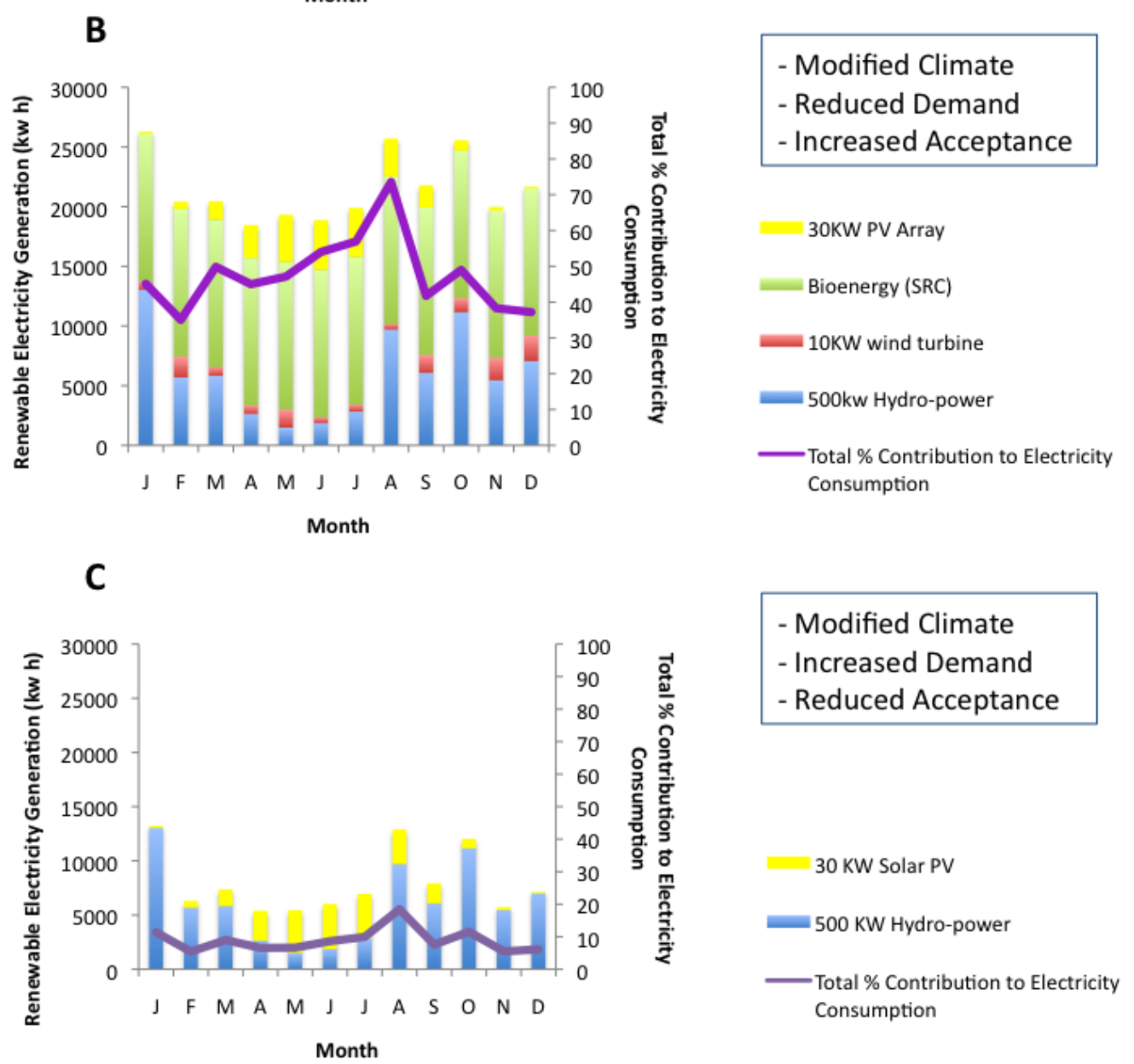

330 Figure 3. Annual plots for scenario A (Current State of Play), B (Low Carbon Adjusted) and C

331 (Reluctant Society), showing renewable electricity generation under modified conditions of

332 climate, demand and acceptance. 
334 case study area (Defra, 2007). The portfolio of renewable energy technologies was

335 subsequently hydro-power (500KW), solar PV array (30KW), small-scale wind (10KW) and

336 SRC bioenergy (19KW CHP generator, assuming feedstock sourced from within the

337 community).

338 On an annual basis this scenario contributed $46 \%$ to the community's annual electricity 339 needs (Figure 3B). Other than the consistent monthly contribution from bioenergy, supply 340 was once again dominated by hydro-power, however wind-power and solar PV also make a 341 significant contribution. This is also complemented by the lower levels of predicted 342 electricity consumption in this scenario.

343 August saw the highest levels of renewable electricity generation which accounted for $34473.6 \%$ of local electricity needs. February was the month which contributed the least to 345 local electricity needs (35\%). This scenario saw the winter and summer day profiles greatly 346 exceed local electricity needs. For the winters day, supply was heavily dominated by hydro347 power (Figure 4B). For the summers day it was a combination of higher summer river flows, 348 the complementary mix of wind-power and solar PV and the lower levels of estimated 349 electricity consumption (Figure $5 \mathrm{~B}$ ). It should be noted that although bioenergy was 350 included in the renewables mix for this scenario (as seen on the annual contribution 351 figures) it was excluded from the daily profiles. This is because it was difficult to determine 352 how much feedstock would be used on an hourly basis. Considering the very high levels of 353 renewable generation for the more 'immediate' renewable technologies such as wind, 354 solar and hydro-power, it was felt that bioenergy would not be used on these days. 
358 This scenario considers the community's renewable energy supply and demand under less

359 favourable conditions. This scenario increases local demand and assumes a modified

360 climate, under which societal acceptance to renewable energy technologies is considered

361 low. The portfolio of renewable energy technologies chosen was subsequently hydro-

362 power (500KW) and a solar PV array (30KW). Hydro-power was chosen because this was by

363 some margin the most favourable renewable technology during the questionnaire and

364 interview stage of phase 2 (Gormally et al., 2013). It was assumed that even in a scenario

365 with societal reluctance towards incorporating renewable technologies, small to medium

366 sized hydro-power would be considered acceptable. Solar PV was included in order to

367 provide some level of seasonal mix and was considered to be the other most likely

368 technology to be accepted under a reluctant future given its perception as a well

369 developed technology in light of the growing numbers of households adopting solar PV

370 occurring the in the UK (Cherrington et al., 2013).

371 Annually this mix contributed $8 \%$ to the community's electricity needs (Figure 3C). August

372 saw the highest contribution (18.5\%) and February the lowest (5.4\%). This was again a

373 balance between the output from the hydro-power and solar PV and the high estimated

374 levels of local electricity consumption. The winters day profile saw an excess of renewable

375 generation of more than 3 times local needs, dominated by the high winter flows and

376 generation from the hydro-power (Figure 4C). The summer day profile saw a contribution

377 of $66 \%$ to local needs (Figure $5 C$ ). 

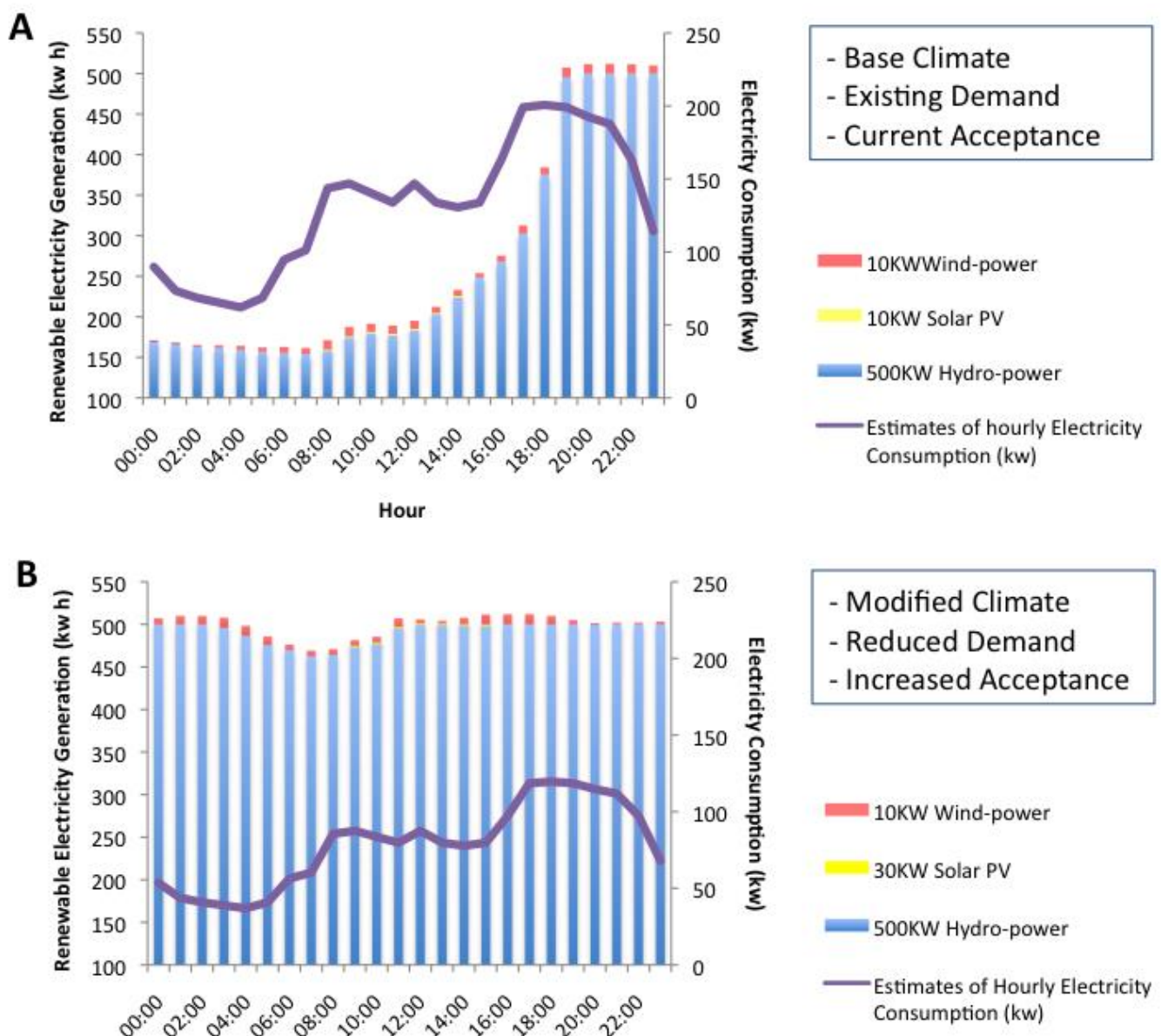

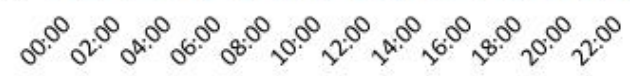

Estimates of Hourly Electricity
Consumption (kw)
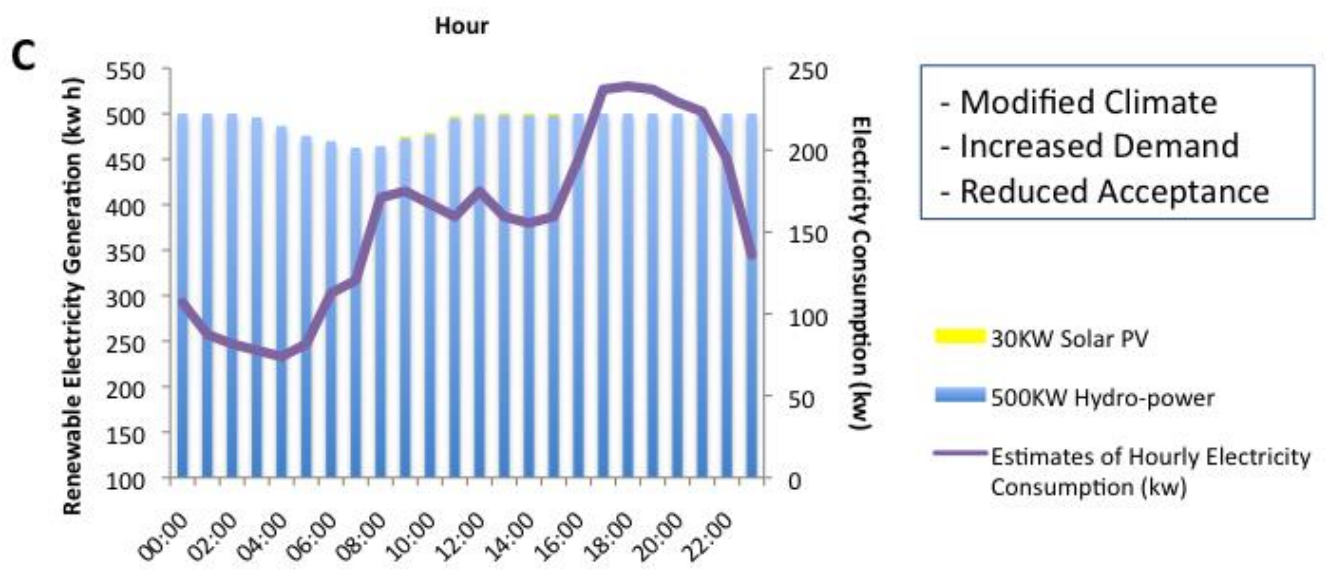

Hour

379 Figure 4. Winter day plots showing hourly renewable electricity generation compared to

380 consumption for scenarios A (Current State of Play), B (Low Carbon Society) and C

381 (Reluctant Society). 


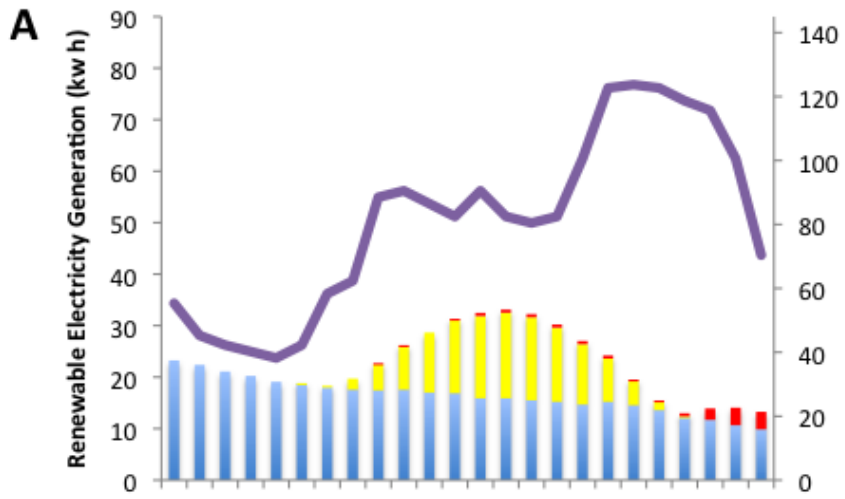

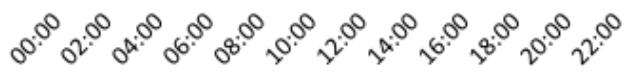

B

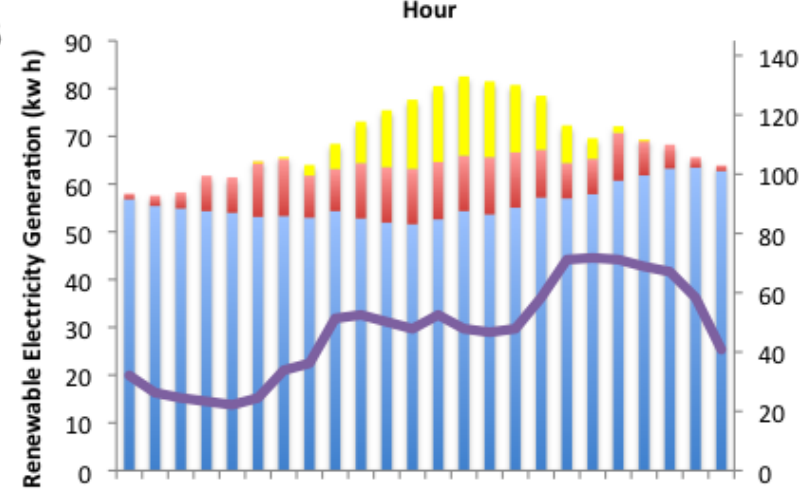

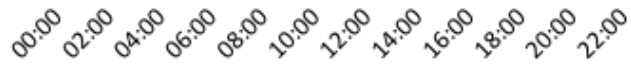

Hour

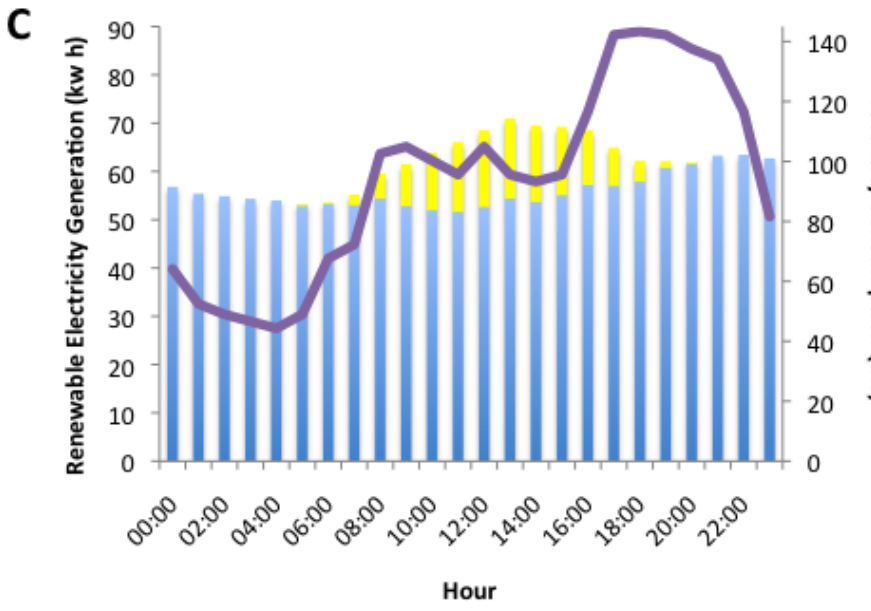

- Base Climate

- Existing Demand

- Current Acceptance

10 KW Wind-power

30 KW Solar PV

500KW Hydro-power

- Estimates of Hourly Electricity Consumption (kw)

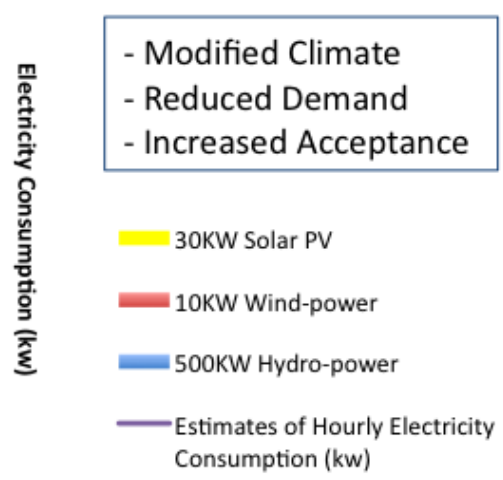

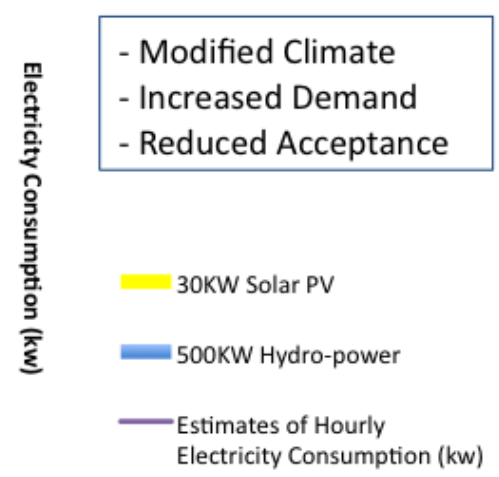

Figure 5. Summer day plots showing hourly renewable electricity generation compared to consumption for scenarios A (Current State of Play), B (Low Carbon Society) and C (Reluctant Society). 
388 This paper set out to describe and explore the final phase of an interdisciplinary mixed389 methods research project that has examined community-based renewable energy in 390 Cumbria, UK. This final phase has produced exploratory energy scenarios for a specific 391 community, Sedgwick in the South Lakeland area of Cumbria, which was identified as 392 having significant resources to support a range of renewable technologies at the 393 community-scale and was also found to have a high level of interest in the concept of local 394 energy by residents (Gormally et al., 2012, Gormally et al., 2013). The exploratory scenarios 395 considered how local demand could be matched with a portfolio of seasonal and weather 396 dependent renewable supply-side options under existing conditions and modified futures. 397 The results are contextualised by comparing results firstly to the UK's renewable electricity 398 target (30-40\% renewable electricity), then to the success on The Isle of Eigg (> $90 \%$ 399 renewable electricity), and finally in relation to export of excess electricity to the national 400 grid (> 100\%).

401 In our regional-scale assessment of renewable resources we concluded that there were 402 sufficient supply-side resources to provide a surplus of electricity to this community on an 403 annual basis (based on existing levels of demand) (Gormally et al., 2012). Here, we find 404 that when community preferences to renewable technologies and scales of development 405 are incorporated at local scales, and when demand and supply are considered at different 406 temporal scales, it is much harder to not only achieve a target of $90 \%$ or greater renewable 407 electricity supply but also to achieve the national target of $30-40 \%$, at the community-scale. 408 Under the 'Current State of Play' scenario which considers existing levels of demand and 409 incorporates local preferences to supply-side options, the downscaling of wind-power and 410 the exclusion of bioenergy has a significant impact on the ability of the community to 411 match demand with supply. It is only during the winters day profile that supply exceeds 
412 demand and this is dominated by the significant level of river flow influencing hydro-power

413 production. This is seen again in the Reluctant Society scenario, which excludes bioenergy

414 and wind-power altogether but does consider the effects of a modified climate in terms of

415 extreme river flows and a slight increase in local demand. The only positive effect from this

416 scenario in terms of matching supply and demand is the increase in summer river flow

417 influencing outputs from hydro-power in both winter and summer day profiles. The Low

418 Carbon Adjusted Society scenario offers a more successful option by reducing levels of local

419 demand, using a modified climate with extremes of river flow and incorporating bioenergy

420 (SRC) into supply options. Under this scenario the community could source approximately

421 half their electricity needs from the accepted portfolio of technologies, and become

422 exporters to the grid on days of high generation, given the reduction in local demand.

423 At the beginning of this paper we set out to argue that under the right societal and

424 environmental conditions, some on-grid communities in the UK could generate a significant

425 proportion of their electricity needs by incorporating a portfolio of local renewable energy

426 resources. The outcomes from previous work on annual resources in this area (Gormally et

427 al., 2012), and the results from the scenarios reported here, would suggest that there is the

428 potential for local resources to meet local demand. However, realising this potential in a

429 way that is acceptable to the community is likely to be problematic. Of course, these

430 scenarios only offer specific narratives of events determined by community attitudes and

431 predictions of future climatic events. These narratives have imposed limitations on the

432 scale of certain technologies eg. wind turbines, and have focussed on certain

433 meteorological effects eg. river flow effecting hydro-power potential. Alternative scenario

434 narratives could be developed, for instance, by increasing the size and/or scale of the

435 generators or by incorporating the effects of changes in other meteorological resources 
436 and their effects on renewable electricity generation. Equally, other scenarios of local

437 demand could be used, for instance, demand patterns influenced by climate modifications.

438 However, what these scenarios do suggest is that unless on-grid communities have the 439 pragmatic response to energy supply that off-grid communities have, they are currently 440 unlikely to successfully integrate these types of renewable portfolios in a way which 441 successfully matches demand with supply. Other measures would need to be incorporated, 442 such as localised storage and/or some form of demand response measure. This currently 443 poses difficulties for on-grid solutions with large-scale electricity storage expensive, and 444 storage at the distributed level unconventionally aligned with existing infrastructures 445 (Jardine and Ault, 2008, Grunewald et al., 2012). Local-level initiatives also offer up 446 interesting questions surrounding management and regulation. Developments of this kind 447 (variable output to the grid) and of this scale will also have implications for grid operators 448 when trying to balance electricity flows around the national grid and in balancing supply 449 with demand on a national scale (Wilson et al., 2010). Understanding the potential role 450 that these types of on-grid community-based developments might have in the future is not 451 only important when trying to envisage changes in future energy behaviours, but 452 additionally when trying to connect these with the role of new energy infrastructures and 453 the impact this will have nationally (and internationally) in configuring our future energy 454 supply. Although on-grid community-based initiatives are on the increase in the UK as 455 evidence by the new implementation of the Community Energy Strategy (DECC, 2014, 456 Hargreaves, 2012), without the right co-ordination of economic, societal and 457 environmental conditions, on-grid communities are unlikely to have enough incentive to 458 become independent from the national grid. However, the concept of self-dependent 459 electricity generating communities is interesting given the increased interest in locally 
owned energy and the social reasoning behind that impetus, for example, disenchantment with current energy suppliers.

462 The approach described in this paper helps shed some light on the role of on-grid 463 community-based renewable energy for a specific case study community in Cumbria, UK. It 464 offers a way of assessing the contribution of renewable supply-side options to local 465 electricity demand under different societal and environmental conditions and on a range of 466 temporal scales. The methodology could also be adapted to incorporate the effects of 467 climate extremes on local demand patterns in addition to supply. Future work could 468 involve assessing the impact of localised energy storage and greater levels of demand-side 469 management in balancing demand and supply at the local-level. Understanding these areas 470 in greater detail would provide a better picture of the role on-grid community-based 471 renewable energy could have in the UK and provide an evidence base on which to make 472 future policy decisions in this area.

473 Cumbria holds many of the attributes associated with aspects of community energy that

474 have been specifically addressed in this paper and previous work in this area, for example, 475 diverse resources, range of community scales and evidence of climatic changes. (Gormally, 476 et al., 2012 and Gormally et al., 2013). Other regions hold similar challenges in terms of 477 understanding the role of community energy, but will hold different solutions. Other 478 regions might have different resources to utilise, be experiencing regionally specific 479 changes in climate and contain communities which hold different concepts of place. These 480 differences would offer alternative options for communities to become 'energy 481 independent' through utilising renewable portfolios. Future research could test out this 482 hypothesis by replicating the methodological approach for alternative regions, both upland 483 and lowland. This would provide a greater evidence base to help understand and inform 484 the future role of community energy in the UK and its potential to become a significant part 
of any future energy system. It could also be used to highlight relevant support that would

need to be put in place if community-based renewables were chosen to be supported

further in the future.

\section{Acknowledgements}

This research was funded as part of an interdisciplinary Ph.D. studentship from the UK

Energy Research Centre and was supported by the UK Research Councils under the Natural

Environment Research Council award NE/G007748/1. The authors would like to acknowledge the Environment Agency for the provision of hydro-power data, the British Atmospheric Data Centre (BADC) for weather data and those residents in Cumbria who generously gave up their time to participate in this study.

\section{References}

Azevedo, J.A., Chapman, L. and Muller, C.L., 2015. Critique and suggested modifications of the degree days methodology to enable long-term electricity consumption assessments: a case study in Birmingham, UK. Meteorological Applications, 22(4), pp.789-796.

Azevedo, Juliana Antunes, Lee Chapman, and Catherine L. Muller. "Urban heat and residential electricity consumption: A preliminary study." Applied Geography 70 (2016): 59-67.

Burt, T. P. \& Ferranti, E. J. S. (2012) Changing patterns of heavy rainfall in upland areas: a case study from northern England. International Journal of Climatology, 32518-532.

Butler, C., Parkhill, K. \& Pidgeon, N. (2012) UKERC Briefing Note: Transforming the UK Energy System: Public Values, Attitudes and Acceptability. Interim findings. $<$ http://psych.cf.ac.uk/home2/butler/Briefing\%20Note\%20l\%20Transforming\%20t he\%20UK\%20Energy\%20System[4].pdf> Accessed:03/06/2013

CEH (2011) Centre for Ecology \& Hydrology: Land Cover Mapping. <http://www.ceh.ac.uk/landcovermapping.html\#LCM2007> Accessed:17/07/2013

Cherrington, R., Goodship, V., Longfield, A. \& Kirwan, K. (2013) The feed-in tariff in the UK: A case study focus on domestic photovoltaic systems. Renewable Energy, 50(0), 421-426.

Climate Change Act (2008) The Climate Change Act. HM Goverment. <http://www.legislation.gov.uk/ukpga/2008/27/pdfs/ukpga 20080027 en.pdf> Accessed:04/06/2013

CSE (2007) Report by the Centre for Sustainable Energy (CSE) and Community Development Xchange (CDX) for; Defra: 'Mobilising individual behavioural change through 
community intitiatives: Lessons for Climate Change'. $<$ http://www.cse.org.uk/pdf/pub1073.pdf $>$ Accessed:12/12/2011

DECC (2009) The UK Renewable Energy Strategy. IN Department of Energy and Climate Change (Ed.). HM Government.

DECC (2012) Capturing the full electricity efficiency potential of the UK. <https://www.gov.uk/government/publications/capturing-the-full-electricityefficiency-potential-of-the-uk--2> Accessed:25/06/2013

Defra (2004) Best Practice Guidelines For Applicants to Defra's Energy Crops Scheme: Growing Short Rotation Coppice. <http://www.naturalengland.org.uk/Images/short-rotation-coppice tcm64262.pdf> Accessed:25/06/2013

Defra (2007) Opportunities and optimum sitings for energy crops $<$ http://archive.defra.gov.uk/foodfarm/growing/crops/industrial/energy/opportuni ties/nw.htm> Accessed:12/12/2011

DUKES (2010) Digest of UK Energy Statistics, LLSOA Electricity and Gas:2009 (experimental). $<$ http://www.decc.gov.uk/en/content/cms/statistics/publications/dukes/dukes.asp $\underline{x}>$ Accessed:20/03/2012

DUKES (2015) Digest of UK Energy Statistics. < https://www.gov.uk/government/uploads/system/uploads/attachment_data/file/ 450302/DUKES_2015.pdf > Accessed:11/02/2016

Energy Savings Trust (2012) Powering the Nation: Household electrcity-using habits revealed. $<$ http://www.energysavingtrust.org.uk/Publications2/Corporate/Research-andinsights/Powering-the-nation-household-electricity-using-habits-revealed> Accessed:24/06/2013

Environment Agency (2010) Opportunity and environmental sensitivity mapping for hydropower in England and Wales.

Ferranti, E. J. S., Whyatt, J. D. \& Timmis, R. J. (2009) Development and application of topographic descriptors for conditional analysis of rainfall. Atmospheric Science Letters, 10(3), 177-184.

Fowler, H. J. \& Ekström, M. (2009) Multi-model ensemble estimates of climate change impacts on UK seasonal precipitation extremes. International Journal of Climatology, 29(3), 385-416.

Gormally, A. M., Pooley, C. G., Whyatt, J. D. \& Timmis, R. J. (2013) "They made gunpowder...yes down by the river there, that's your energy source": attitudes towards community renewable energy in Cumbria. Local Environment, 1-18.

Gormally, A. M., Whyatt, J. D., Timmis, R. J. \& Pooley, C. G. (2012) A regional-scale assessment of local renewable energy resources in Cumbria, UK. Energy Policy, 50(0), 283-293.

Greene, S., Morrissey, M. \& Johnson, S. E. (2010) Wind Climatology, Climate Change, and Wind Energy. Geography Compass, 4(11), 1592-1605.

Grunewald, P. H., Cockerill, T. T., Contestabile, M. \& Pearson, P. J. G. (2012) The sociotechnical transition of distributed electricity storage into future networks-System value and stakeholder views. Energy Policy, 50449-457.

Hargreaves, T., Hielscher, S., Seyfang, G. \& Smith, A. (2012) Exploring the Role of Intermediaries in UK Community Energy: Grassroots Innovation and Niche Development'.Science, Society \& Sustainability (3S) Working Paper 2012-12. $<$ http://www.3s.uea.ac.uk/publications/exploring-role-intermediaries-ukcommunity-energy-grassroots-innovations-and-niche-deve> Accessed:04/06/2013

Harrison, G. P. \& Whittington, H. W. (2002) Susceptibility of the Batoka Gorge hydroelectric scheme to climate change. Journal of Hydrology, 264(1-4), 230-241. 
Heiskanen, E., Johnson, M., Robinson, S., Vadovics, E. \& Saastamoinen, M. (2010) Lowcarbon communities as a context for individual behavioural change. Energy Policy, 38(12), 7586-7595.

Jardine, C. N. \& Ault, G. W. (2008) Scenarios for examination of highly distributed power systems. Proceedings of the Institution of Mechanical Engineers, Part A: Journal of Power and Energy, 222(7), 643-655.

Kowalski, K., Stagl, S., Madlener, R. \& Omann, I. (2009) Sustainable energy futures: Methodological challenges in combining scenarios and participatory multi-criteria analysis. European Journal of Operational Research, 197(3), 1063-1074.

Malby, A. R., Whyatt, J. A., Timmis, R. J., Wilby, R. L. \& Orr, H. G. (2007) Long-term variations in orographic rainfall: analysis and implications for upland catchments. Hydrological Sciences Journal-Journal Des Sciences Hydrologiques, 52(2), 276-291.

Meehl, G. A., T.F. Stocker, W.D. Collins, P. Friedlingstein, A.T. Gaye, J.M. Gregory, A. Kitoh, R. Knutti, J.M. Murphy, A. Noda, S.C.B. Raper, I.G. Watterson, A.J. Weaver and Z.-C. Zhao., (2007) Global Climate Projections. IN Solomon, S., D. Qin, M. Manning, Z. Chen, M. Marquis, K.B. Averyt, M. Tignor, Miller, H.L., \& (Eds.) Climate Change 2007: The Physical Science Basis. Contribution of Working Group I to the Fourth Assessment Report of the Intergovernmental Panel on Climate Change. Cambridge, United Kingdom and New York, NY, USA, Cambridge University Press,

MIDAS (2013) MIDAS Land Surface Stations data (1853-current). British Atmospheric Data Centre, 2006. <http://badc.nerc.ac.uk/view/badc.nerc.ac.uk ATOM dataent ukmo-midas> Accessed:25/06/2013

ONS (2011) Information Note: Super Output Areas (SOAs). Office for National Statistics.

Osborn, T. J., Hulme, M., Jones, P. D. \& Basnett, T. A. (2000) Observed trends in the daily intensity of United Kingdom precipitation. International Journal of Climatology, 20(4), 347-364.

Renewable Energy Strategy (2009) The UK Renewable Energy Strategy. Crown Copyright. <http://www.official-documents.gov.uk/document/cm76/7686/7686.pdf> Accessed:04/06/2013

Sustainability First (2012) GB Electricity Demand - 2010 and 2025: Initial Brattle Electricity Demand-Side Model - Scope for Demand Reduction and Flexiable Response. <http://www.sustainabilityfirst.org.uk/gbelec.html> Accessed:18/07/2013

Tenerelli, P. \& Carver, S. (2012) Multi-criteria, multi-objective and uncertainty analysis for agro-energy spatial modelling. Applied Geography, 32(2), 724-736.

Warren, C. R. \& McFadyen, M. (2010) Does community ownership affect public attitudes to wind energy? A case study from south-west Scotland. Land Use Policy, 27(2), 204213.

Watson, J., Sauter, R., Bahaj, B., James, P., Myers, L. \& Wing, R. (2008) Domestic microgeneration: Economic, regulatory and policy issues for the UK. Energy Policy, 36(8), 3095-3106.

Wilson, I. A. G., McGregor, P. G. \& Hall, P. J. (2010) Energy storage in the UK electrical network: Estimation of the scale and review of technology options. Energy Policy, 38(8), 4099-4106.

Yadoo, A., Gormally, A. \& Cruickshank, H. (2011) Low-carbon off-grid electrification for rural areas in the United Kingdom: Lessons from the developing world. Energy Policy, 39(10), 6400-6407. 